\title{
SARS-CoV2 Infection in Hematopoietic Stem Cell Transplant recipients: A Case Series from a Tertiary Cancer Centre in India
}

\author{
Akhil Rajendra $^{1,6} \cdot$ Anant Gokarn $^{1,6} \cdot$ Sumeet Mirgh $^{1,6}{ }_{(\mathbb{D}} \cdot$ Rahul Ravind $^{1,6}$ • \\ Anuj Singh ${ }^{1,6} \cdot$ Vasu Babu Goli ${ }^{1,6} \cdot$ Sachin Punatar ${ }^{1,6}$ - Akanksha Chichra ${ }^{1,6}$. \\ Prashant Tembhare ${ }^{2,6} \cdot$ Nikhil Patkar $^{2,6}$ - Vivek Bhat ${ }^{3,6}$ - Preeti Chavan ${ }^{4}$. \\ Bhakti Trivedi $^{5,6} \cdot$ Amit Joshi $^{1,6} \cdot$ Navin Khattry ${ }^{1,6}$ (I)
}

Received: 29 January 2021 / Accepted: 1 May 2021/Published online: 13 May 2021

(C) Indian Society of Hematology and Blood Transfusion 2021

\section{Dear Editor,}

Severe acute respiratory syndrome Coronavirus-2 (SARSCoV-2) virus associated COVID-19 (coronavirus disease) pandemic, has led to more than 2.5 million deaths worldwide. Hematopoietic stem cell transplant (HCT) recipients may be at a greater risk of morbidity and mortality due to their immunosupressed state [1]. Here, we report 6 cases of SARS-CoV-2 infection in HCT recipients.

Between May and September 2020, six HCT recipients were diagnosed with SARS-CoV-2 infection at our centre, based on reverse transcriptase polymerase chain reaction (RTPCR) on nasopharyngeal swab. Baseline characteristics of all the six patients are shown in Table 1. Severity of COVID-19 disease was graded as per WHO ordinal scale [2]. We used triplet antiviral combination with Lopinavir/ Ritonavir (LPV/r), Ribavirin (RBV) and Interferon $\beta 1 \mathrm{~b}$ (IFN $\beta 1 b$ ) in the initial period of pandemic and then remdesivir (once available in India) for moderate-severe COVID-19 or for mild COVID-19 with ongoing

Navin Khattry

nkhattry@gmail.com

1 Department of Medical Oncology, ACTREC, Tata Memorial Centre, Mumbai, India

2 Hematopathology Department, ACTREC, Tata Memorial Centre, Mumbai, India

3 Department of Microbiology, ACTREC, Tata Memorial Centre, Mumbai, India

4 Composite Laboratory, ACTREC, Tata Memorial Centre, Mumbai, India

5 Department of Anaesthesiology, Pain and Critical Care, Tata Memorial Centre, Mumbai, India

6 Homi Bhabha National Institute, Mumbai, India immunosuppressants. Tocilizumab was used for severe COVID-19, as per physician discretion. Nasopharyngeal swab was repeated every 2 weeks till negativity and antibodies to SARS-CoV-2 were tested after 2 weeks of initial RTPCR positivity and then 2 weekly.

We found that 5 of these 6 patients required prolonged time to clear the viral infection, with median time to RTPCR negativity of 31 days (Table 1). Three patients (patient A, C and D) developed neutralising $\operatorname{IgG}$ antibodies ( $\operatorname{IgG}$ ) to SARS-CoV-2 at 83 days, 22 days and 31 days post infection respectively. However, Patient $\mathrm{C}$ who developed antibodies at day 22, continued to remain persistently RTPCR positive for SARS-CoV-2 (Table 1). At a median follow-up of 40 days, all patients in our cohort are alive.

With emerging evidence, treatment options in COVID19 are becoming clearer. However, there is no standard of care for immunocompromised patients, especially post HCT recipients.

In a phase II randomized trial, triplet combination consisting of oral LPV/r (400 mg/100 mg) and RBV $400 \mathrm{mg}$ twice daily (14 days) along with IFN $\beta 1 \mathrm{~b}$ was compared with LPV/r alone. Along with significantly improved clinical response, the triplet combination resulted in early nasopharyngeal negativity [3]. Amongst the 6 patients in our series, 3 received triplet antivirals, and showed rapid defervesence with clinical improvement. However, in contrast to Hung et al. [3], the time to negative nasopharyngeal swab was longer in our patients who received this combination. Production of excessive cytokines results in severe inflammatory responses in the lung resulting in severe COVID-19 manifestations and use of Tocilizumab, has been found to abrogate this inflammation [4]. In patient A, Tocilizumab was used twice in view of impending respiratory failure on third day and fifth day of infection resulting in rapid clinical benefit and radiological response. 
Table 1 Clinical characteristics of patients with SARS-CoV-2 infections post BMT

\begin{tabular}{|c|c|c|c|c|c|c|}
\hline & \begin{tabular}{|l|} 
Patient $A$ \\
\end{tabular} & Patient B & Patient $C$ & Patient $D$ & Patient $E$ & Patient $F$ \\
\hline $\begin{array}{l}\text { Baseline } \\
\text { Diagnosis }\end{array}$ & $\begin{array}{l}\text { JAK2 Neg } \\
\text { Primary } \\
\text { Myelofibrosis }\end{array}$ & $\begin{array}{l}\text { Multiple myeloma, } \\
\text { IgG Kappa }\end{array}$ & $\begin{array}{l}\text { Philadelphia } \\
\text { Positive ALL } \\
\text { in CR } 1\end{array}$ & $\begin{array}{l}\text { Primary } \\
\text { progressive non- } \\
\text { hodgkin } \\
\text { lymphoma }\end{array}$ & $\begin{array}{l}\text { AML FLT3- } \\
\text { ITD+ } \\
\text { NPM1+ }\end{array}$ & $\begin{array}{l}\text { Philadelphi } \\
\text { a Positive } \\
\text { ALL with } \\
\text { early CNS } \\
\text { Relapse }\end{array}$ \\
\hline Age & 61 & 42 & 34 & 25 & 37 & 23 \\
\hline Gender & $M$ & $F$ & $M$ & $M$ & $F$ & $M$ \\
\hline $\begin{array}{l}\text { Time from } \\
\text { transplant }\end{array}$ & 78 months & 36 months & 5 months & 9 months & 9 months & 57 months \\
\hline $\begin{array}{l}\text { Type of } \\
\text { Transplant }\end{array}$ & $\begin{array}{l}\text { Allogeneic } \\
\text { matched } \\
\text { sibling } \\
\text { transplant } \\
\end{array}$ & $\begin{array}{l}\text { Autologous Stem } \\
\text { Cell Transplant }\end{array}$ & \begin{tabular}{|l|} 
Allogeneic \\
matched \\
sibling \\
transplant \\
\end{tabular} & $\begin{array}{l}\text { Autologous Stem } \\
\text { Cell Transplant }\end{array}$ & \begin{tabular}{|l|} 
Allogenic \\
matched \\
sibling \\
transplant \\
\end{tabular} & $\begin{array}{l}\text { Allogenic } \\
\text { matched } \\
\text { sibling } \\
\text { transplant }\end{array}$ \\
\hline $\begin{array}{l}\text { Concomitant } \\
\text { GVHD(Yes/No) }\end{array}$ & No & NA & Yes & NA & No & No \\
\hline $\begin{array}{l}\text { Presenting } \\
\text { symptoms }\end{array}$ & $\begin{array}{l}\text { Fever, Sore } \\
\text { throat }\end{array}$ & $\begin{array}{l}\text { Fever, Chills, Cough, } \\
\text { Breathlessness, Sore } \\
\text { throat, Ageusia }\end{array}$ & $\begin{array}{l}\text { Fever, Cough, } \\
\text { Sore throat }\end{array}$ & $\begin{array}{l}\text { Fever, Headache, } \\
\text { Myalgia }\end{array}$ & \begin{tabular}{|l|} 
Fever, Sore \\
throat, \\
Rhinorrhea
\end{tabular} & $\begin{array}{l}\text { Breathlessn } \\
\text { ess, Chest } \\
\text { pain }\end{array}$ \\
\hline $\begin{array}{l}\text { Duration of } \\
\text { symptoms } \\
\text { before CovID } \\
\text { diagnosis } \\
\end{array}$ & 3 days & 2 days & 3 days & 1 day & 3 days & 3 days \\
\hline $\begin{array}{l}\text { Severity of } \\
\text { COVID infection } \\
\text { (as per WHO } \\
\text { ordinal scale) }\end{array}$ & Severe & Mild & Mild & Mild & Mild & Mild \\
\hline Treatment given & $\begin{array}{l}\text { Tocilizumab } 4 \\
\mathrm{mg} / \mathrm{kg} \times 2 \\
\text { doses } \\
\text { Lopinavir/ } \\
\text { Ritonavir } \\
\text { (400/100 } \mathrm{mg} \text { ) } \\
\mathrm{bd} \\
\text { Ribavirin } 400 \\
\mathrm{mg} \text { BD } \times 21 \\
\text { days } \\
\mathrm{IFN} \text { beta1b } 8 \\
\text { MU every } \\
\text { alternate days } \\
\times 2 \text { doses } \\
\end{array}$ & $\begin{array}{l}\text { Lopinavir/Ritonavir(4 } \\
00 / 100 \mathrm{mg}) \text { bd X } 10 \\
\text { days } \\
\text { Ribavirin } 400 \mathrm{mg} \mathrm{BD} \\
\text { x } 10 \text { days } \\
\text { IFN beta } 1 \mathrm{~b} 8 \mathrm{MU} \\
\text { every alternate days } \\
\text { x } 3 \text { doses }\end{array}$ & $\begin{array}{l}\text { Lopinavir/Rito } \\
\text { navir } \\
(400 / 100 \mathrm{mg}) \\
\text { bd } \mathrm{X} 10 \text { days } \\
\text { Ribavirin } 400 \\
\mathrm{mg} \mathrm{BD} \times 10 \\
\text { days } \\
\text { IFN beta } 8 \mathrm{MU} \\
\text { every } \\
\text { alternate days } \\
\times 3 \text { doses }\end{array}$ & $\begin{array}{l}\text { Only supportive } \\
\text { treatment }\end{array}$ & $\begin{array}{l}\text { Only } \\
\text { supportive } \\
\text { care }\end{array}$ & $\begin{array}{l}\text { Injection } \\
\text { Remedesvir } \\
\text { ( } 200 \mathrm{mg} \text { IV } \\
\text { on day } 1 \\
\text { followed by } \\
100 \mathrm{mg} \text { iv } \\
\text { day } 2 \text { to day } \\
\text { 5) }\end{array}$ \\
\hline $\begin{array}{l}\text { Requirement of } \\
\frac{\text { High Flow }}{\text { Oxygen }}\end{array}$ & $\begin{array}{l}\text { Yes } \\
\text { (High flow } \\
\text { nasal cannula) }\end{array}$ & No & No & No & No & No \\
\hline $\begin{array}{l}\text { Anticoagulation } \\
\text { given }\end{array}$ & $\begin{array}{l}\text { Yes } \\
\text { Prophylactic }\end{array}$ & $\begin{array}{l}\text { Yes } \\
\text { (Prophylactic) }\end{array}$ & $\begin{array}{l}\text { Yes } \\
\text { (Prophylactic) }\end{array}$ & No & No & Yes \\
\hline $\begin{array}{l}\text { Total duration of } \\
\text { admission (days) }\end{array}$ & 36 & 10 & 15 & 10 & 10 & 5 \\
\hline $\begin{array}{l}\text { Any triggering or } \\
\text { worsening of } \\
\text { GVHD }\end{array}$ & No & NA & $\begin{array}{l}\text { Yes } \\
\text { upper Gut } \\
\text { GVHD }\end{array}$ & NA & No & No \\
\hline $\begin{array}{l}\text { Baseline } \\
\text { Absolute } \\
\text { Iymphocyte } \\
\text { count }\left(\times 10^{9} / L\right)\end{array}$ & 1.32 & 0.81 & 1.11 & 1.2 & 1.07 & 3.57 \\
\hline$\frac{\text { Nadir ALC }}{\left(\mathrm{X} 10^{9} / \mathrm{L}\right)}$ & 0.42 & 0.81 & 0.43 & NA & 0.83 & 3.34 \\
\hline $\begin{array}{l}\text { Baseline IL-6 } \\
(\mathrm{pg} / \mathrm{ml})\end{array}$ & 21 & 8.97 & 11.58 & 5 & 11.7 & 1.2 \\
\hline $\begin{array}{l}\text { Baseline Covid } \\
\text { swab RT PCR } \\
\text { Cycling } \\
\text { Threshold } \\
\text { (CT)values }\end{array}$ & $\begin{array}{l}\text { E gene - } \\
28.61 \\
\text { RdRP gene - } \\
32.06\end{array}$ & $\begin{array}{l}\text { E gene- } 25 \\
\text { RdRp gene - } 27\end{array}$ & $\begin{array}{l}\text { E gene - 16.9 } \\
\text { RdRp gene - } \\
19.7\end{array}$ & $\begin{array}{l}\text { E gene }-9.6 \\
\text { RdRp gene- } 11.3\end{array}$ & $\begin{array}{l}\text { E gene- } \\
31.5 \\
\text { RdRp- } \\
32.5\end{array}$ & $\begin{array}{l}\text { E gene - } \\
28.4 \\
N \text { gene- } \\
28.9\end{array}$ \\
\hline $\begin{array}{l}\text { Time to Covid } \\
\text { swab negativity }\end{array}$ & 31 days & 22 days & \begin{tabular}{|l|} 
Not yet \\
negative \\
(2 months \\
since \\
diagnosis) \\
\end{tabular} & 53 days & 15 days & 19 days \\
\hline $\begin{array}{l}\text { Covid Specific } \\
\text { Antibody } \\
\text { Formation (IgG) } \\
\text {-YES/NO }\end{array}$ & Yes & No & Yes & Yes & No & No \\
\hline $\begin{array}{l}\text { Time to Antibody } \\
\text { formation }\end{array}$ & 83 days & $\begin{array}{l}\text { Negative (40 days } \\
\text { post COVID infection) }\end{array}$ & 22 days & 31 days & $\begin{array}{l}\text { Negative } \\
\text { (21 days } \\
\text { post COVID } \\
\text { infection) }\end{array}$ & Negative \\
\hline Final Outcome & $\begin{array}{l}\text { Alive } \\
\text { COVID RT-PCR } \\
\text { negative } \\
\text { COVID } \\
\text { Antibody } \\
\text { positive }\end{array}$ & $\begin{array}{l}\text { Alive } \\
\text { COVID RT-PCR } \\
\text { negative } \\
\text { COVID Antibody } \\
\text { negative }\end{array}$ & $\begin{array}{l}\text { Alive } \\
\text { COVID RT-PCR } \\
\text { positive } \\
\text { COVID } \\
\text { Antibody } \\
\text { positive }\end{array}$ & $\begin{array}{l}\text { Alive } \\
\text { COVID RT-PCR } \\
\text { negative } \\
\text { COVID Antibody } \\
\text { positive }\end{array}$ & \begin{tabular}{|l|} 
Alive \\
COVID RT- \\
PCR \\
negative \\
COVID \\
Antibody \\
negative
\end{tabular} & $\begin{array}{l}\text { Alive } \\
\text { COVID RT- } \\
\text { PCR } \\
\text { negative } \\
\text { COVID } \\
\text { Antibody } \\
\text { negative }\end{array}$ \\
\hline
\end{tabular}

Legends: JAK2: Janus kinase 2, IgG: Immunoglobin G, ALL: Acute Lymphoblastic Leukemia, NLPHL: Nodular Lymphocyte Predominant Hodgkin Lymphoma, AML: Acute Myeloid Leukemi

FT3-ITD: FMS Like Tyrosine kinase 3 Internal Tandem Duplication, NPM1: Nucleophosmin 1, GVHD: Graft Versus Host Disease, WHO: World Health Organisation, RT-PCR: Reverse Transcriptase Polymerase Chain Reaction, E gene: Envelope small membrane protein, RdRp gene: RNA dependent RNA polymerase, $\mathrm{N}$ gene: Nucleoprotein gene. 

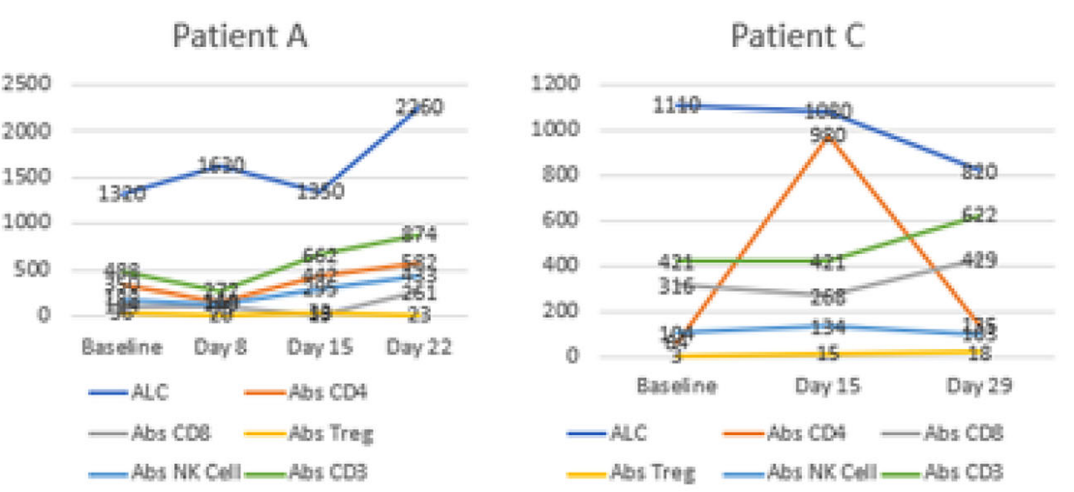

Patient E

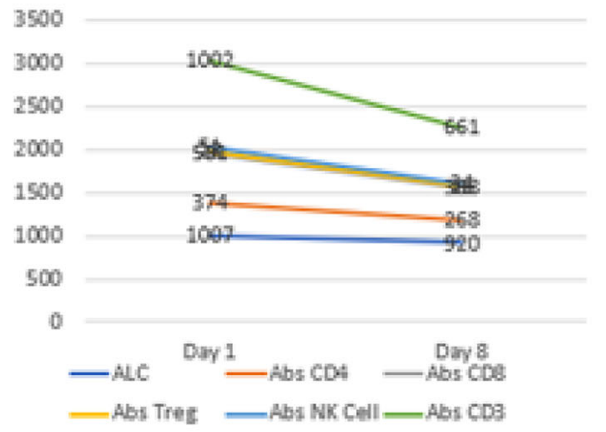

$\mathrm{X}$ - Days since the diagnosis of COVID-19

$Y$ - Cell count $(/ \mathrm{microL})$

Abs - Absolute; ALC - Absolute lymphocyte count, Treg - T Regulatory Cell count, NK Cell - Absolute Natural Killer Cell Count

Fig. 1 Immune cell profile of Allogeneic stem cell transplant recipients post COVID infection

Thus, this case series highlights that use of antivirals (triplet antivirals and Remdesivir) and tocilizumab results in favorable outcome in post HCT patients with COVID-19 infection.

We recorded the immune kinetics of our allogeneic HCT patients during the course of illness (Fig. 1). In the early phases of infection, there was a decrease in the Absolute NK Cell, CD3, CD4 and CD8. By Day 8-15 there was a rise in these parameters. The graph pattern of patient $\mathrm{E}$ is in stark contrast to those of patients A and C. All the T-cell subsets and NK-cells appear to have stabilized, likely because this patient was diagnosed in late stages of the infection.

With the FDA authorizing the use of remdesivir, a more tolerated drug with better outcomes, for the treatment of moderate and severe COVID-19 infection, the place of triplet combination of $\mathrm{LPV} / \mathrm{r}, \mathrm{RBV}$ and IFN $\beta 1 \mathrm{~b}$ in the therapeutic armamentarium is not clear, nevertheless, it still remains an alternative, if remdesivir is unavailable.

\section{References}

1. Saraceni F, et al Severe COVID-19 in a patient with chronic graftversus-host disease after hematopoietic stem cell transplant successfully treated with ruxolitinib. Transpl Infect Dis n/a: e13401.

2. https://www.who.int/blueprint/priority-diseases/key-action/COVID-19 _Treatment_Trial_Design_Master_Protocol_synopsis_Final_1802 2020.pdf. Last Accessed 10 Jan 2021.

3. Hung IF-N et al (2020) Triple combination of interferon beta-1b, lopinavir-ritonavir, and ribavirin in the treatment of patients admitted to hospital with COVID-19: an open-label, randomised, phase 2 trial. Lancet 395:1695-1704

4. Toniati P, et al. (2020) Tocilizumab for the treatment of severe COVID-19 pneumonia with hyperinflammatory syndrome and acute respiratory failure: a single center study of 100 patients in Brescia, Italy. Autoimmun Rev 19, 102568

Publisher's Note Springer Nature remains neutral with regard to jurisdictional claims in published maps and institutional affiliations. 